\title{
Low Dose Total Skin Electron Beam Radiation in Cutaneous T-Cell Lymphoma: Review
}

\author{
Misty Gamble1,2, Elizabeth Tocci ${ }^{3}$, Jennifer A. DeSimone ${ }^{2,4}$ \\ ${ }^{1}$ Department of Melanoma and Cutaneous Oncology, MedStar Washington Hospital Center, Washington DC, \\ USA \\ ${ }^{2}$ Department of Dermatology, MedStar Georgetown University Hospital, Washington DC, USA \\ ${ }^{3}$ University of Massachusetts Medical School, Worcester, USA \\ ${ }^{4}$ Melanoma and Skin Oncology, INOVA Fairfax Hospital, Fairfax, USA \\ Email: gamblemf@yahoo.com
}

Received 28 September 2014; revised 25 October 2014; accepted 20 November 2014

Academic Editor: Sibu P. Saha, University of Kentucky, USA

Copyright (C) 2014 by authors and Scientific Research Publishing Inc.

This work is licensed under the Creative Commons Attribution International License (CC BY). http://creativecommons.org/licenses/by/4.0/

(c) (i) Open Access

\begin{abstract}
The treatment of advanced stage MF is especially challenging as single agent overall response rates are in the $35 \%$ range and chronic recurrence is the rule. The treatment of CTCL across all stages of disease is aimed at the goal of achieving and sustaining remission. Increasingly, low dose total skin electron beam therapy (TSEBT) is being utilized as a skin directed component in combination therapy for advanced stage CTCL. Researchers are seeking to better define the utility of low dose TSEBT as a method of debulking skin disease while simultaneously treating other disease compartments and in combination with sustained maintenance therapies of both the skin directed and systemic varieties. Data exists showing the efficacy of low dose TSEBT in early and advanced disease. There is also data documenting prolonged treatment responses with TSEBT plus adjuvant skin directed therapies such as PUVA and topical nitrogen mustard. Emerging data examining the role of low dose TSEBT in the prestem cell transplant preparation is also promising. This brief review summarizes the utility of low dose TSEBT in multiagent treatment regimens in CTCL.
\end{abstract}

\section{Keywords}

Cutaneous T-Cell Lymphoma, Mycosis Fungoides, Total Skin Electron Beam Therapy, Hematopoietic Stem Cell Transplantation 


\section{Introduction}

Cutaneous lymphomas represent 3.9\% of all non-Hodgkin lymphomas [1]. Mycosis fungoides (MF) and sezary syndrome (the leukemic variant) constitute approximately $53 \%$ of all cutaneous lymphomas, and are collectively termed cutaneous T-cell lymphoma (CTCL) [2]. Mycosis fungoides is the most common variant of CTCL and is defined as a malignancy of skin resident CD4+ T effector memory cells with characteristic loss of CD7 and CD26 [3] [4].

The annual age-adjusted incidence is 9.6 cases per million people in the United States, and it appears to have increased over the last 3 decades [5]. The incidence of MF increases with advancing age and a gender predilection toward men is observed. In the United States, African Americans are affected more than Caucasians [6].

The etiology of cutaneous T cell lymphoma (CTCL) remains largely unknown. However, it is thought to arise in the setting of chronic antigenic stimulation resulting in uncontrolled clonal expansion of malignant CD4+ effector memory T lymphocytes [7]. While no specific mutation has been identified, multiple studies have shown evidence of an altered transcriptome with aberrant gene expression patterns unique to CTCL, suggesting epigenetic shifts in the pathophysiology of the disease [8]. Due to the rarity of MF, there is limited, and often, conflicting data on the risk factors for developing the disease. Recently, however, obesity, cigarette smoking (for $40+$ years), eczema, family history of multiple myeloma, and certain occupations like crop farming, woodworking, painting, and carpentering have been proposed as potential risk factors while moderate to vigorous exercise is thought to be a protective factor [9]. The lesions of MF often present on sunprotected skin as erythematous scaly patches which may progress to infiltrated plaques or tumors [10].

Treatment of advanced stage MF is especially challenging as single agent overall response rates are in the 35\% range and chronic recurrence is the rule [11] [12]. Stem cell transplant offers the only chance for a definitive cure [11]. The European Organization for Research and Treatment of Cancer (EORTC) published treatment guidelines according to clinical stage [12] [13]. The atypical lymphocytes in MF are exquisitely radiosensitive rendering radiation therapy a useful treatment modality in early and advanced stage disease [14]. Increasingly, low dose total skin electron beam therapy (TSEBT) is being utilized as skin directed component in combination therapy for advanced stage CTCL. In this article, we present a review of TSEBT and highlight the efficacy of low-dose TSEBT use in conjunction with adjuvant therapy.

\section{Technique Review}

Total skin electron beam therapy for the treatment of widespread skin lesions of MF was first conducted on two patients by Trump et al. in 1951 and involved a multi-day process during which patients assumed various postures on a treatment bed while the bed was moved under a giant cathode tube accelerator [15]. The advent of the Stanford Medical Linear Accelerator improved the treatment regimen, allowing for the efficient, uniform treatment of the entire skin surface with a six-field technique [10]. Modifications to the electron beam administration technique continue to improve the uniformity of dosing, as the higher the field number, the fewer occurrences of overlapping electron beams and less adverse cutaneous side effects [10] [16]. McGill RTSEI: The technique for rotational total skin electron irradiation is having the patient stand on a slowly rotating platform in a large uniform linear accelerator electron field $(E o=3.5 \mathrm{MeV})$. The beam is scattered by the transmission ionization chamber and by a special lead/aluminum scattering filter, and then degraded by a sheet of Lucite. A Farmer chamber is used as a patient dose monitor and a method for absolute dose calibration is presented. The field is uniform to within $\pm 5 \%$ for dimensions of $180 \times 40 \mathrm{~cm}^{2}$. The surface dose for rotational therapy is equal to $45 \%$ of the maximum dose in a stationary beam. The rotating beam exhibits a dose maximum on the surface, falls to $80 \%$ at $0.5 \mathrm{~cm}$, and has an X-ray contamination of approximately $4 \%$. The surface dose rate is about $25 \mathrm{cGy} / \mathrm{min}$ for the rotating beam. The stationary beam exhibits a dose maximum at $4 \mathrm{~mm}$ in tissue, a surface dose of $93 \%, 80 \%$ dose at a depth of $1 \mathrm{~cm}$, a practical range of $1.75 \mathrm{~cm}$, and an X-ray contamination of $2.5 \%$. The rotational total skin electron irradiation significantly reduces the patient treatment and setup time and solves the problem of beam matching, when compared to standard multiple-beam techniques [17]. Depth of penetration and precision of field alignment may be finely controlled using the 6 pose and rotational techniques.

\section{Ideal Dose Review}

In the past, TSEBT was used in high doses as a palliative therapy in patients with extensive disease. Although it was fairly successful as a monotherapy, recurrence rates were still very high (Table 1). 
Table 1. Efficacy of TSEBT as initial treatment for MF.

\begin{tabular}{ccc}
\hline Stage of MF & Complete remission & 10 year progression free survival \\
\hline IA, IIA (T1N1) & $95 \%$ & $50 \%$ \\
IB, IIA (T2N1) & $90 \%$ & $<20 \%$ \\
IIB, limited regional disease & & $15 \%$ \\
III & $75 \%$ & $66 \%$ \\
If B0 & & $15 \%$ \\
If B1 & $>70 \%$ & Low \\
IVA & $>70 \%$ & $0 \%$ \\
IVB & & $0 \%$ \\
\hline
\end{tabular}

Efficacy rates (response and duration of remission post-treatment) are increased in earlier stages of disease. Data from Jones et al. 2002 [13].

Recommendations for the ideal total dose are based on extent of skin involvement (T stage) and desired endpoint of palliation vs. remission. The EORTC Guidelines recommend total doses of 31 - 36 Gy over 6 - 10 weeks, broken down into 1 - 1.5 Gy every other day. Electrons should penetrate $4 \mathrm{~mm}$ deep into the skin, resulting in the use of low energy electrons (4-5.5 MeV) [18]. Fuks et al., using a 6-field technique, found that the magnitude of initial response varied inversely with $\mathrm{T}$ stage at onset of treatment. Patients with eczematous and limited plaque MF (T1 and 2) had 100\% complete response (CR) (12/12) with high dose radiation (20 - 35 Gy). Patients with thick plaques and tumors had lower rates of complete remission (59\% for plaque and 30\% for tumors) but enjoyed palliative benefits, including temporary ( 1 - 3 years) resolution of lesions, re-epithelialization of skin ulcers and clearance of infections [19]. This study spurred recommendations for higher radiation doses of $>20$ Gy per TSEBT course [20].

\section{Efficacy Data}

A retrospective review of $102 \mathrm{MF}$ patients treated with low-dose TSEBT noted overall response rates (ORR) in patients who received 5 to $<10$ Gy of $90 \%, 10$ to $<20 \mathrm{~Gy}$ of $98 \%$, and 20 to $<30 \mathrm{~Gy}$ of $97 \%$. Overall survival (OS) and progression-free survival (PFS) in patients administered 10 to $<20$ Gy and 20 to $<30$ Gy compared to those receiving conventional doses of $>30$ Gy were not significantly different [21].

Separate investigators have published small studies evaluating the role of low dose TSEBT in the treatment of M.F. Kamstrup et al. found that total doses of 4 Gy broken up into 4 fractions resulted in short term, partial remission in early stage MF (IB-II). For the 10 patients in the study, the objective response rate (ORR) was $80 \%$, complete response rate (CR) was $2 \%$, and time to progression (TTP) was 2.7 months [22] [23]. Lindholm et al. found that for the 10 patients with early stage MF (IB-II) treated with the same fractionated 4 Gy dose, there was a $100 \%$ ORR and a $10 \%$ CR.

Another study evaluating the efficacy of total doses of 10 Gy in patients with T2-T4 disease, cited 90\% ORR, CR of 70\% and TTP averaging 4.2 months [23] [24]. Low dose TSEBT has the potential benefit of reduced toxicity, including no late symptoms of skin necrosis and unremitting dermatitis, subsequently allowing for repeated administrations. It is recognized that low dose TSEBT as monotherapy results in short remission times [23]. Therefore, low dose TSEBT for CTCL is likely to be of most benefit when utilized as the skin directed component of combination therapy including a long-term maintenance agent.

Harrison et al. observed a clinically significant response rate (defined as $>50 \%$ of skin clearing) of $>96 \%$ for T2-T4 disease at both low dose and conventional doses of TSEBT; however the low dose group had fewer complete responses [21] (Table 2).

\section{Side Effects}

Side effects from electron beam therapy are usually limited to the skin, hair, and nails. Common side effects include transient erythema, onycholysis 2 - 4 months after treatment, temporary hair loss, temporary skin hyper- 
pigmentation, anhydrosis/hypohydrosis, desquamation, xerosis, blisters, and skin pain or discomfort [10] [20] [25]. With repeated courses, reports of other skin side effects such as telangiectasias and atrophy increased. Lloyed et al. reported the most common toxicity rates and grades in a retrospective review of 85 patients with mycosis fungoides receiving TSEBT. The patients were treated with a total of 89 courses of TSEBT. They found the most common cutaneous toxicities to be radiation erythema/desquamation (76\%), blisters (52\%), hyperpigmentation (50\%), skin pain/discomfort (48\%), and xerosis (38\%). $21 \%$ of their patients exhibited grade 1 toxicities, $67 \%$ had grade 2, and $10 \%$ had grade 3 toxicities. None of their patients developed grade 4 or 5 toxicities. Amongst African American patients, hyperpigmentation was the most frequently reported skin toxicity. Edema, eye irritation and fatigue were the most common nonskin toxicities reported. They also noted that $32 \%$ of their patients who were receiving a total dose of 30 to 36 Gy developed severe skin infections requiring treatment with either oral or intravenous antibiotics during TSEBT [26] (Table 3).

\section{TSEBT as Component of Combination Therapy}

Conventional doses of TSEBT followed by adjuvant therapies have had mixed results in the literature,

Table 2. Efficacy of low dose TSEBT in MF.

\begin{tabular}{|c|c|c|c|c|c|}
\hline Stage & Total dose & $\begin{array}{l}\text { Number of } \\
\text { fractions }\end{array}$ & $\begin{array}{l}\text { Objective response } \\
\text { rate (ORR) }\end{array}$ & $\begin{array}{c}\text { Complete } \\
\text { response rate (CRR) }\end{array}$ & $\begin{array}{l}\text { Time to } \\
\text { progression }\end{array}$ \\
\hline \multicolumn{6}{|l|}{ IB-II } \\
\hline Kamstrup et al. 2008 [22] [23] & 4 Gy & 4 & $80 \%$ & $2 \%$ & 2.7 months \\
\hline Lindholm et al. [23] & 4 Gy & & $100 \%$ & $10 \%$ & \\
\hline \multicolumn{6}{|l|}{ IB-IV (T2-T4) } \\
\hline Kamstrup et al. 2012 [23] [24] & $10 \mathrm{~Gy}$ & 1Gy per week in 4 fractions & $90 \%$ & $70 \%$ & 4.2 months \\
\hline Harrison et al. 2011 [21] & $5-<10 \mathrm{~Gy}$ & & $90 \%$ & $16 \%$ & \\
\hline
\end{tabular}

Table 3. Side effects of TSEBT [10] [20] [25] [26].

\begin{tabular}{|c|c|c|}
\hline \multicolumn{3}{|c|}{ Common side effects: limited to skin, hair and nails } \\
\hline Erythema/desquamation & & Transient \\
\hline \multicolumn{3}{|l|}{ Bullae } \\
\hline Skin hyperpigmentation & Tel & ost common side effect in African Americans \\
\hline \multicolumn{3}{|l|}{ Skin pain/discomfort } \\
\hline \multicolumn{3}{|l|}{ Xerosis } \\
\hline Onycholysis & \multicolumn{2}{|r|}{2 - 4 months post treatment } \\
\hline Hair loss & \multicolumn{2}{|r|}{ Temporary } \\
\hline \multicolumn{3}{|l|}{ Anhydrosis/hypohydrosis } \\
\hline \multicolumn{3}{|c|}{ Other side effects } \\
\hline \multicolumn{3}{|c|}{ Skin infection } \\
\hline \multicolumn{3}{|c|}{ Edema } \\
\hline \multicolumn{3}{|c|}{ Eye irritation } \\
\hline \multicolumn{3}{|c|}{ Fatigue } \\
\hline \multicolumn{3}{|c|}{ Side effects particularly from repeated courses } \\
\hline \multicolumn{3}{|c|}{ Telangiectasias } \\
\hline \multicolumn{3}{|c|}{ Skin atrophy } \\
\hline
\end{tabular}


depending on the type of additional therapies used [27]. Harrison et al. suggests that the use of partial low-dose TSEBT followed by adjuvant systemic therapy may be just as effective as the conventional dose in overall response rates [21]. Although certain adjuvant therapies may have increased disease-free survivals, such as is seen with PUVA and also ECP in late stage disease, overall survival does not seem to be increased by adjuvant therapies [25] [27]-[31].

In a retrospective review from Stanford, conventional doses of TSEBT with HN2 (nitrogen mustard; mechlorethamine) were compared with HN2 therapy alone in MF patients with cutaneous T2-T3 disease. Investigators found that TSEBT statistically significant superiority and increased complete responses over HN2 alone. This study also found that TSEBT with subsequent adjuvant HN2 treatment prolonged the duration of response [32].

Wilson et al. retrospectively analyzed data from patients with erythrodermic MF (stages III-IVB) who had adjuvant ECP (before, during, or after) TSEBT (total dose of 32 - 40 Gy). In patients with complete response to TSEBT, the addition of ECP significantly increased disease free survival. At both 2 and 3 years, $49 \%$ of patients with TSEB monotherapy were disease-free, whereas the TSEBT plus ECP group had $93 \%$ at 2 year and $83 \%$ at 3-year disease-free survival, respectively. Overall survival was not different between the groups, but cause specific survival was just barely significantly improved at 2 and 3 years for the TSEBT plus ECP group [31].

\section{Repeat Courses of TSEBT}

Limited data is available analyzing the efficacy and tolerability of subsequent TSEBT after initial low dose TSEBT. One study examined 5 CTCL patients treated with up to 3 separate courses of TSEBT (36 Gy, 18 Gy and 12 Gy were the mean doses for the first, second and third courses respectively) [33]. Although response rates decreased with subsequent cycles, $60 \%$ of patients receiving TSEBT for the third time had a complete response to TSEBT. Another study analyzed results of 15 patients after their second treatment of TSEBT [34]. Six patients had a complete response and 9 showed a partial response with side effects including skin dryness, telangiectasias, pigment changes, alopecia. The initial selection of low dose TSEBT reserves the option of utilizing TSEBT again in future treatment of refractory and advanced disease.

\section{Low Dose TSEBT in Preparation for Hematopoietic Stem Cell Transplant}

In patients with advanced CTCL, even the most promising new drug therapies achieve temporary remission, with disease recurrence being the rule. The only possibility for a cure in CTCL is allogeneic hematopoietic stem cell transplantation (HSCT). The goal is to completely eradicate all evidence of skin, lymph node and blood disease immediately prior to HSCT, through pre-transplant treatment and conditioning regimens. The use of high-dose chemo-radiotherapy conditioning regimens combined with HSCT results in complete response in a small number of reported cases [35]. To date, there are relatively few case reports and case series which discuss the use of TSEBT prior to HSCT in patients with advanced or refractory CTCL. In a review by Duarte et al., they identified 4 studies (Bigler et al., 1991; Gabriel et al., 2007; Olavarria et al., 2001; Russell-Jones et al., 2001) which included a total of 9 patients previously treated with TSEBT prior to autologous HSCT [35]. All 9 patients achieved complete clinical responses; however, the median progression-free survival ranged from less than 100 days to approximately 7 months. Olavarria et al. reported better disease control in some patients after their relapse, with patients responding to conventional therapies post transplantation [36]. A retrospective study by Duvic et al. included 15 patients with advanced CTCL who received a conditioning regimen of TSEBT with 36 Gy followed by reduced-intensity allogenic stem cell transplantation between July 2001 and July 2008 [37]. Median age at transplantation was 50 years; transplantation was performed at a median of 4 years after diagnosis. At 2 years, the non-relapse mortality-free survival was $88 \%$, and the progression-free survival at 2 years was $53 \%$. The 2-year overall survival was 79\%. Of the 13 living patients, 11 were in complete remission and 2 had good disease control. The authors suggested that the use of TSEBT to debulk the skin immediately before HSCT may have led to a decrease in the severity of post-transplantation GVHD. They also speculated that TSEBT could assist in the reduction of skin antigen-presenting cells, which could possibly prevent the initiation of CD4+ T-cell proliferation that occurs in response to Class II HLA-restricted antigen presentation from donor cells matched with HLA antigens.

\section{Discussion}

The treatment of CTCL across all stages of disease is aimed at the goal of achieving and sustaining remission. 
There has been a paradigm shift in terms of our concept of the role for TSEBT and it is no longer regarded as a simple palliative measure for advanced and refractory disease. Low dose TSEBT is easier, more cost effective, and better tolerated than traditional full dose regimens. Increasingly, researchers are seeking to better define the utility of low dose TSEBT as a method of debulking skin disease while simultaneously treating other disease compartments and in combination with sustained maintenance therapies of both the skin directed and systemic varieties. Data exists showing the efficacy of low dose TSEBT in early and advanced disease. There is also data documenting prolonged treatment responses with TSEBT plus adjuvant skin directed therapies such as PUVA and topical nitrogen mustard [18] [21] [25] [27]-[32]. (Studies show that conventional doses of TSEBT plus adjuvant therapy seem to have a better effect on diminishing skin symptoms of all stages of CTCL than TSEBT therapy alone [21]). Emerging data examining the role of low dose TSEBT in the prestem cell transplant preparation are promising [35]-[37].

\section{Conclusion}

In conclusion, further studies are certainly needed to better define treatment algorhithims utilizing low dose TSEB in the treatment of CTCL. It is clear, however, that low dose TSEBT should be considered as a safe and effective skin directed therapy, best given as one component of a combination regimen in early and advanced stages of disease in CTCL.

\section{References}

[1] Bradford, P.T., Devesa, S.S., Anderson, W.F. and Toro, J.R. (2009) Cutaneous Lymphoma Incidence Patterns in the United States: A Population-Based Study of 3884 Cases. Blood, 113, 10. http://dx.doi.org/10.1182/blood-2008-10-184168

[2] Willemze, R., Jaffe, E.S., Burg, G., Cerroni, L., Berti, E. and Swerdlow, S.H. (2005) WHO-EORTC Classification for Cutaneous Lymphomas. Blood, 105, 3768-3785. http://dx.doi.org/10.1182/blood-2004-09-3502

[3] James, W.D., Berger, T. and Elston, D. (2011) Mycosis Fungoides. Andrews' Diseases of the Skin: Clinical Dermatology_Expert Consult-Online. 11th Edition, Saunders, Philadelphia.

[4] Wood, G.S., Hong, S.R., Sasaki, D.T., Abel, E.A., Hoppe, R.T., Warnke, R.A. and Morhenn, V.B. (1990) Leu-8/CD7 Antigen Expression by CD3+ T Cells: Comparative Analysis of Skin and Blood in Mycosis Fungoides/Sézary Syndrome Relative to Normal Blood Values. Journal of the American Academy of Dermatology, 22, 602-607. http://dx.doi.org/10.1016/0190-9622(90)70080-2

[5] Criscone, V.D. and Weinstock, M.A. (2007) Incidence of Cutaneous T-Cell Lymphoma in the United States, 1973-2002. Archives of Dermatology, 143, 854-859.

[6] Hinds, G.A. and Heald, P. (2009) Cutaneous T-Cell Lymphoma in Skin of Color. Journal of the American Academy of Dermatology, 60, 359-375. http://dx.doi.org/10.1016/j.jaad.2008.10.031

[7] Girardi, M., Heald, P.W. and Wilson, L.D. (2004) The Pathogenesis of Mycosis Fungoides. The New England Journal of Medicine, 350, 1978-1988. http://dx.doi.org/10.1056/NEJMra032810

[8] Wong, H. (2013) Novel Biomarkers, Dysregulated Epigenetics, and Therapy in Cutaneous T-Cell Lymphoma. Discovery Medicine, 16, 71-78.

[9] Aschebrook-Kilfoy, B., Cocco, P., La Vecchia, C., Chang, E.T., Vajdic, C.M., Kadin, M.E., et al. (2014) Medical History, Lifestyle, Family History, and Occupational Risk Factors for Mycosis Fungoides and Sezary Syndrome: The Interlymph Non-Hodgkin Lymphoma Subtypes Project. Journal of the National Cancer Institute Monographs, 48, 98105. http://dx.doi.org/10.1093/jncimonographs/lgu008

[10] Hoppe, R.T., Wood, G.S. and Abel, E.A. (1990) Mycosis Fungoides and the Sezary Syndrome: Pathology, Staging, and Treatment. Current Problems in Cancer, 14, 293-371. http://dx.doi.org/10.1016/0147-0272(90)90018-L

[11] Schlaak, M., Pickenhain, J., Theurich, S., Skoetz, N., von Bergwelt-Baildon, M. and Kurschat, P. (2013) Allogeneic Stem Cell Transplantation versus Conventional Therapy for Advanced Primary Cutaneous T-Cell Lymphoma. Cochrane Database of Systematic Reviews, 2013, Article ID: CD008908. http://dx.doi.org/10.1002/14651858.CD008908.pub3

[12] Trautinger, F., Knobler, R., Willemze, R., et al. (2006) EORTC Consensus Recommendations for the Treatment of Mycosis Fungoides/Sezary Syndrome. European Journal of Cancer, 42, 1014-1030. http://dx.doi.org/10.1016/j.ejca.2006.01.025

[13] Jones, G.W., Kacinski, B.M., Wilson, L.D., et al. (2002) Total Skin Electron Radiation in the Management of Mycosis Fungoides: Consensus of the European Organization for Research and Treatment of Cancer (EORTC) Cutaneous 
Lymphoma Project Group. Journal of the American Academy of Dermatology, 47, 364-370. http://dx.doi.org/10.1067/mjd.2002.123482

[14] Whittaker, S.J. and Foss, F.M. (2007) Efficacy and Tolerability of Currently Available Therapies for the Mycosis Fungoides and Sezary Syndrome Variants of Cutaneous T-Cell Lymphoma. Cancer Treatment Reviews, 33, 146-160. http://dx.doi.org/10.1016/j.ctrv.2006.08.006

[15] Trump, J.G., Wright, K.A., Evans, W.W., et al. (1953) High Energy Electrons for the Treatment of Extensive Superficial Malignant Lesions. American Journal of Roentgenology, Radium Therapy, and Nuclear Medicine, 69, 623-629.

[16] Lo, T.C., Salzman, F.A., Moschella, S.L., Tolman, E.L. and Wright, K.A. (1979) Whole Body Surface Electron Irradiation in the Treatment of Mycosis Fungoides. An Evaluation of 200 Patients. Radiology, 130, 453-457. http://dx.doi.org/10.1148/130.2.453

[17] Podgorsak, E.B., Pla, C., Pla, M., Lefebvre, P.Y. and Heese, R. (1983) Physical Aspects of a Rotational Total Skin Electron Irradiation. Medical Physics, 10, 159-168. http://dx.doi.org/10.1118/1.595296

[18] Moraes, F.Y., Carvalho, H., Hanna, S.A., et al. (2014) Literature Review of Clinical Results of Total Skin Electron Irradiation (TSEBT) of Mycosis Fungoides in Adults. Reports of Practical Oncology and Radiotherapy, 19, 92-98. http://dx.doi.org/10.1016/j.rpor.2013.08.003

[19] Fuks, Z.Y., Bagshaw, M.A. and Farber, E.M. (1973) Prognostic Signs and the Management of the Mycosis Fungoides. Cancer, 32, 1385-1395. http://dx.doi.org/10.1002/1097-0142(197312)32:6<1385::AID-CNCR2820320617>3.0.CO;2-\#

[20] Levi, J.A. and Wiernik, P.H. (1975) Management of Mycosis Fungoides-Current Status and Future Prospects. Medicine (Baltimore), 54, 73-88. http://dx.doi.org/10.1097/00005792-197501000-00004

[21] Harrison, C., Young, J., Navi, D., et al. (2011) Revisiting Low-Dose Total Skin Electron Beam Therapy in Mycosis Fungoides. International Journal of Radiation Oncology, Biology, Physics, 81, e651-e657. http://dx.doi.org/10.1016/j.ijrobp.2011.01.023

[22] Kamstrup, M.R., Specht, L., Skovgaard, G.L. and Gniadecki, R. (2008) A Prospective, Open-Label Study of Low-Dose Total Skin Electron Beam Therapy in Mycosis Fungoides. International Journal of Radiation Oncology, Biology, Physics, 71, 1204-1207. http://dx.doi.org/10.1016/j.ijrobp.2007.11.039

[23] Kazmierska, J. (2014) Clinical Results of the Total Skin Electron Irradiation of the Mycosis Fungoides in Adults. Conventional Fractionation and Low Dose Schemes. Reports of Practical Oncology and Radiotherapy, 19, 99-103. http://dx.doi.org/10.1016/j.rpor.2013.08.008

[24] Kamstrup, M.R., Lindahl, L.M., Gniadecki, R., et al. (2012) Low-Dose Total Skin Electron Beam Therapy as a Debulking Agent for Cutaneous T-Cell Lymphoma: An Open-Label Prospective Phase II Study. British Journal of Dermatology, 166, 399-404. http://dx.doi.org/10.1111/j.1365-2133.2011.10670.x

[25] Kaye, F.J., Bunn Jr., P.A., Steinberg, S.M., et al. (1989) A Randomized Trial Comparing Combination Electron-Beam Radiation and Chemotherapy with Topical Therapy in the Initial Treatment of Mycosis Fungoides. The New England Journal of Medicine, 321, 1784-1790. http://dx.doi.org/10.1056/NEJM198912283212603

[26] Lloyd, S., Chen, Z., Foss, F., Girardi, M. and Wilson, L. (2013) Acute Toxicity and Risk of Infection during Total Skin Electron Beam Therapy for Mycosis Fungoides. Journal of the American Academy of Dermatology, 69, 537-543. http://dx.doi.org/10.1016/j.jaad.2013.04.063

[27] Roberge, D., Muanza, T., Blake, G., Shustik, C., Vuong, T. and Freeman, C.R. (2007) Does Adjuvant Alpha-Interferon Improve Outcome When Combined with Total Skin Irradiation for Mycosis Fungoides? British Journal of Dermatology, 156, 57-61. http://dx.doi.org/10.1111/j.1365-2133.2006.07559.x

[28] Navi, D., Riaz, N., Levin, Y.S., Sullivan, N.C., Kim, Y.H. and Hoppe, R.T. (2011) The Stanford University Experience with Conventional-Dose, Total Skin Electron-Beam Therapy in the Treatment of Generalized Patch or Plaque $\left(\mathrm{T}_{2}\right)$ and Tumor $\left(\mathrm{T}_{3}\right)$ Mycosis Fungoides. Archives of Dermatology, 147, 561-567. http://dx.doi.org/10.1001/archdermatol.2011.98

[29] Quiros, P.A., Jones, G.W., Kacinski, B.M., et al. (1997) Total Skin Electron Beam Therapy Followed by Adjuvant Psoralen/Ultraviolet—A Light in the Management of Patients with T1 and T2 Cutaneous T-Cell Lymphoma (Mycosis Fungoides). International Journal of Radiation Oncology, Biology, Physics, 38, 1027-1035. http://dx.doi.org/10.1016/S0360-3016(97)00127-2

[30] Wilson, L.D., Licata, A.L., Braverman, I.M., et al. (1995) Systemic Chemotherapy and Extracorporeal Photochemotherapy for T3 and T4 Cutaneous T-Cell Lymphoma Patients Who Have Achieved a Complete Response to Total Skin Electron Beam Therapy. International Journal of Radiation Oncology, Biology, Physics, 32, 987-995. http://dx.doi.org/10.1016/0360-3016(95)00073-8

[31] Wilson, L.D., Jones, G.W., Kim, D., et al. (2000) Experience with Total Skin Electron Beam Therapy in Combination with Extracorporeal Photopheresis in the Management of Patients with Erythrodermic (T4) Mycosis Fungoides. Journal of the American Academy of Dermatology, 43, 54-60. http://dx.doi.org/10.1067/mjd.2000.105510 
[32] Chinn, D.M., Chow, S., Kim, Y.H. and Hoppe, R.T. (1999) Total Skin Electron Beam Therapy with or without Adjuvant Topical Nitrogen Mustard or Nitrogen Mustard Alone as Initial Treatment of T2 and T3 Mycosis Fungoides. International Journal of Radiation Oncology, Biology, Physics, 43, 951-958. http://dx.doi.org/10.1016/S0360-3016(98)00517-3

[33] Wilson, L.D., Quiros, P.A., Kolenik, S.A., et al. (1996) Additional Courses of Total Skin Electron Beam Therapy in the Treatment of Patients with Recurrent Cutaneous T-Cell Lymphoma. Journal of the American Academy of Dermatology, 35, 69-73. http://dx.doi.org/10.1016/S0190-9622(96)90499-5

[34] Becker, M., Hoppe, R.T. and Knox, S.J. (1995) Multiple Courses of High-Dose Total Skin Electron Beam Therapy in the Management of Mycosis Fungoides. International Journal of Radiation Oncology, Biology, Physics, 32, $1445-1449$. http://dx.doi.org/10.1016/0360-3016(94)00590-H

[35] Duarte, R.F., Schmitz, N., Servitje, O. and Sureda, A. (2008) Hematopoietic Stem Cell Transplantation for Patients with Primary Cutaneous T-Cell Lymphoma. Bone Marrow Transplant, 41, 597-604. http://dx.doi.org/10.1038/sj.bmt.1705968

[36] Olavarria, E., Child, F., Woolford, A., Whittaker, S.J., Davis, J.G., McDonald, C., et al. (2001) T-Cell Depletion and Autologous Stem Cell Transplantation in the Management of Tumour Stage Mycosis Fungoides with Peripheral Blood Involvement. British Journal of Haematology, 114, 624-631. http://dx.doi.org/10.1046/j.1365-2141.2001.02919.x

[37] Duvic, M., Donato, M., Dabaja, B., Richmond, H., Singh, L., Wei, W., et al. (2010) Total Skin Electron Beam and Non-Myeloablative Allogeneic Hematopoietic Stem-Cell Transplantation in Advanced Mycosis Fungoides and Sezary Syndrome. Journal of Clinical Oncology, 28, 2365-2372. http://dx.doi.org/10.1200/JCO.2009.25.8301 
Scientific Research Publishing (SCIRP) is one of the largest Open Access journal publishers. It is currently publishing more than 200 open access, online, peer-reviewed journals covering a wide range of academic disciplines. SCIRP serves the worldwide academic communities and contributes to the progress and application of science with its publication.

Other selected journals from SCIRP are listed as below. Submit your manuscript to us via either submit@scirp.org or Online Submission Portal.
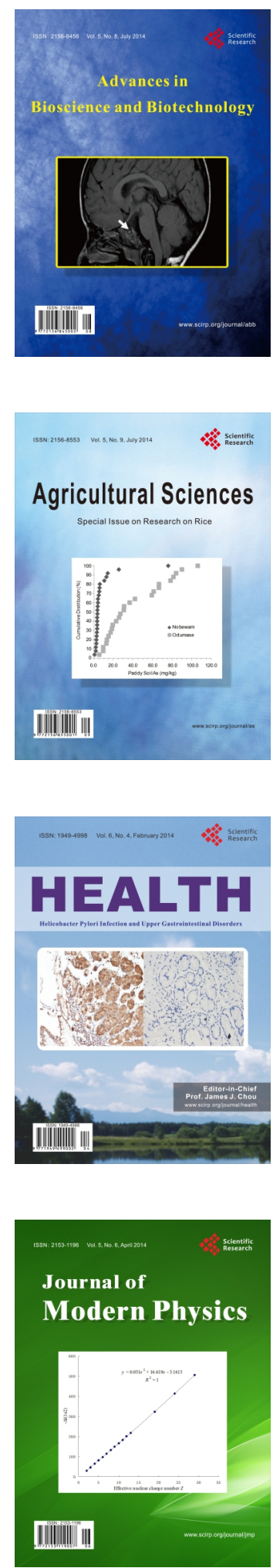
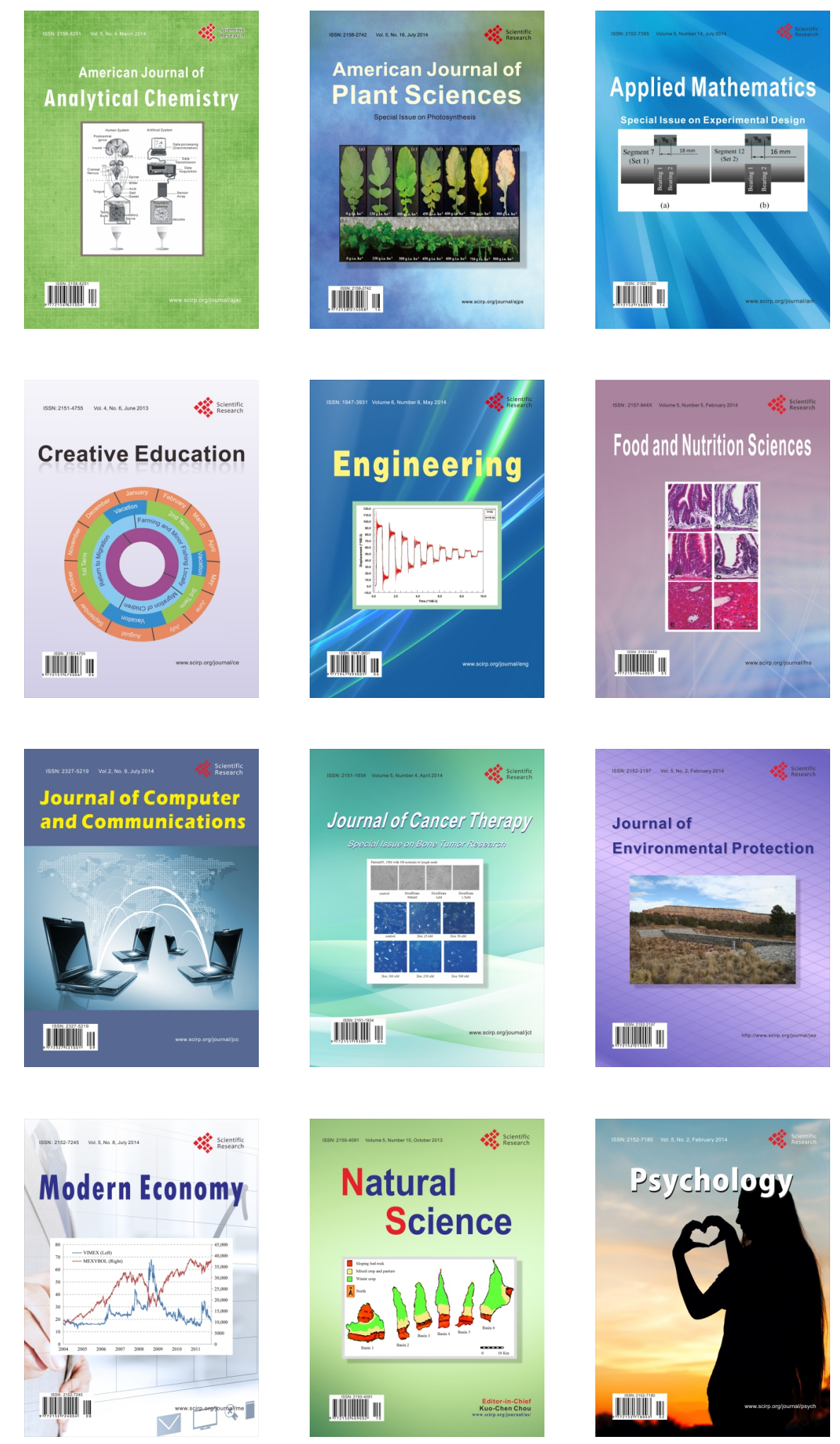